\title{
Rancang Bangun Aplikasi Mobile Learning Pada Sistem Operasi Android
}

\author{
A'la Syauqi ${ }^{1)}$, Maret Dewi K. ${ }^{2)}$ \\ Fakultas Sains dan Teknologi, Jurusan Teknik Informatika, Universitas Islam Negeri \\ Maulana Malik Ibrahim Malang, Jl. Gajayana 50 Malang \\ 1)
}

\begin{abstract}
Teknologi diharapkan menjadi solusi kebutuhan masadepan. Pada saat ini hampir setiap orang memiliki telepon seluler. Teknologi telepon seluler selalu berkembang dari masa ke masa hingga sekarang dimana telepon seluler dapat terkoneksi dengan internet dan mengambil data dari server melalui sistem cloud computing. Salah satu pemanfaatan dari sistem ini adalah untuk pendidikan. Dengan demikian pendidikan dapat diusahakan dapat dinikmati semua orang dimanapun dan kapanpun. Telepon seluler yang terkoneksi dengan internet dapat berperan sebagai pendamping peserta didik untuk belajar, yang sering disebut dengan istilah mobile learning. Namun di sisi lain perangkat mobile learning memiliki keterbatasan sumber daya dan keragaman platform sehingga diperlukan rancangan yang mampu menjamin kompatibilitas.
\end{abstract}

Kata Kunci: telepon seluler, cloud computing, internet, mobile learning

\section{Pendahuluan}

Perkembangan teknologi telepon seluler sedemikian cepat dan dapat dirasakan di seluruh dunia. Tidak memandang umur, dari kalangan anak- anak sekitar umur 10 tahun hingga lansia sudah memilikinya. Terutama pada kalangan anak muda tiap tahun jumlah penggunanya terus meningkat. Hampir semua mempunyai telepon seluler, beberapa orang merasa tidak cukup hanya mempunyai sebuah telepon seluler. Perkembangan ini dapat dimanfaatkan dalam dunia pendidikan yang disebut mobile learning.

Mobile learning merupakan bagian dari pembelajaran elektronik atau lebih di kenal dengan e-learning ${ }^{[1]}$. Terkait dengan jumlah pengguna perangkat bergerak yang banyak di Indonesia, mobile learning dapat dijadikan sebagai salah satu alternatif untuk memecahkan permasalahan dalam bidang pendidikan, terutama masalah pemerataan akses infomasi pendidikan, kualitas konten pembelajaran yang berupa materi pembelajaran dengan bentuk teks ataupun gambar disertai dengan contohcontoh soal serta peningkatan kualitas pengajar agar lebih baik dalam membuat atau menyampaikan materi pembelajaran dan mengelola kegiatan belajar mengajar. Mobile learning mempermudah belajar dan interaksi antara peserta didik dengan materi pelajaran. Pengembang mobile learning harus mengetahui perbedaan pendekatan-pendekatan dalam belajar agar dapat memilih strategi pembelajaran yang tepat. Strategi pembelajaran harus dipilih untuk memotivasi para pembelajar.

Mobile learning memiliki beberapa kelebihan diantaranya adalah indepensi dalam pembelajaran. Namun di sisis lain, perangkat pembelajaran mobile learning memiliki keterbatasan sumber daya dan keragaman platform sehingga diperlukan rancangan yang mampu menjamin kompalitibilitas dan inteoperabilitas.

Paper ini akan membahas desain dan rancangan aplikasi mobile learning berbasis android untuk dunia pendidikan, khususnya di kalangan perguruan tinggi.

\section{Metode}

A. Analisa Permasalahan Sistem

Dalam sebuah perancangan e-learning berbasis mobile, diperlukan perhatian 
khusus pada karakteristik penggunan dan keterbatasan device-nya. E-learning yang ada tidak begitu saja diaplikasikan ke lingkungan mobile learning. Beberapa aspek yang menjadi perhatian dalam perancangan aplikasi mobile learning adalah sebagai berikut: ${ }^{[2]}$

1) Keterbatasan Resource

Dibanding dengan perangkat deskop yang didukung oleh hardware yang lebih powerfull, perangkat mobile sangat terbatas dalam hal resource. Hal ini menyebabkan penggunaan resource pada proses komputasi mobile harus dilakukan secara efisien dan seefektif mungkin. Keterbatasan resource disini adalah keterbatasan proses komputasi.

2) Keterbatasan Hardware

Keterbatasan hardware yaitu pada pemakaian baterai dan keterbatasan memori. Penghematan baterai pada penggunaan smartphone android dilakukan dengan meminimasi gambar dan animasi. Tampilan lebih banyak menggunakan teks dan button. Tampilan gambar hanya ditampilkan secara sederhana dan seperlunya saja.

Untuk menghemat memori maka aplikasi mengalokasikan memori seoptimal dan seefisien mungkin, sedangkan untuk mengatasi keterbatasan proses komputasi maka perangkat lunak akan melakukan komputasi dan menggunakan thread seminimum mungkin.

\section{3) Keterbatasan Jaringan}

Untuk mengurangi penggunaan internet secara terus menerus, maka aplikasi ini harus mampu memberi dukungan opererasi secara offline sehingga tidak harus terhubung secara terus-menerus dengan server.

4) Device yang pervasif

Perangkat bergerak memiliki bentuk kecil, mudah dibawa kemana- mana, dan dapat berpindah tangan sehingga dibutuhkan solusi untuk persoalan sosial maupun pesoalan teknis ini. Diperlukan adanya mekanisme proteksi on-device untuk melindungi data sensitive.

5) Skema integrasi
Banyak aplikasi nirkabel bergerak yang membutuhkan integrasi dengan banyak sistem back-end atau middleware berbeda. Saat ini terdapat beberapa teknologi yang dapat digunakan, diantaranya adalah protokol biner proprietary, Framework RPC, messaging serta $\mathrm{xml}$ web sercive. Masing- masing teknologi ini memiliki kekurangan dan kelebihan.

6) Kenyamanan pengguna

Merancang aplikasi yang mudah digunakan adalah tantangan besar bagi pengembang. Beberapa hal yang perlu diperhatikan. Tampilan yang menarik, tidak membosankan, tidak terlalu padat, dan pemanfaatan thread untuk proses yang lama, prefensi pengguna dan penyediaan deployment descriptor untuk kemudahan instalasi.

B. Analisa Kebutuhan

Analisis kebutuhan merupakan analisis terhadap komponen- komponen yang digunakan untuk pembuatan sistem aplikasi mobile learning. Komponen yang dibutuhkan terbagi menjadi dua macam, yaitu komponen software dan hardware.

1) Software

Software adalah program atau aplikasi komputer lain yang dibutuhkan untuk membangun sebuah sistem. Software yang dibutuhkan untuk proses pembuatan aplikasi mobile learning adalah sebagai berikut:

a) Windows $X P$

Windows XP merupakan sistem operasi yang menjembatani antara komputer dan user. Windows XP digunakan karena support dan compatible dengan software lain yang dibutuhkan dalam pembuatan aplikasi mobile learning ini:

b) Java Development Kit (JDK) versi 1.6.0_13

JDK merupakan paket platform java yang terdiri dari berbagai macam library, JVM, compiler dan debugger.

c) Java Runtime Evironment (JRE) versi 7

Supaya sebuah program java dapat dijalankan, maka file berekstensi. Java harus dikompilasi menjadi file bytecode. JRE berfungsi untuk mengeksekusi file 
bytecode yang memungkinkan pemakai untuk menjalankan program java.

d) Android SDK

Android SDK adalah tools API (Applikation Programming Interface) yang diperlukan untuk mulai mengembangkan aplikasi pada platform Android menggunakan bahasa pemrograman java. Android merupakan subset perangkat lunak untuk ponsel yang meliputi sistem operasi, middleware dan aplikasi kunci yang di release oleh Google.

e) Eclipse

Eclipse adalah sebuah IDE (Integrated Development Environment) untuk mengembangkan perangkat lunak dan dapat dijalankan di semua platform (platform-independent

f) $D B M S M y S Q L$

MySQL merupakan database server di mana pemrosesan data terjadi di server dan client hanya mengirim data dan memindah data. Pengaksesan dapat dilakukan dimana saja dan oleh siapa saja dengan catatan komputer telah terhubung ke server.

2) Hardware

Hardware adalah perangkat keras yang digunakan untuk menunjang dalam pembuatan sebuah sistem. Dalam pembuatan aplikasi mobile learning, hardware yang dibutuhkan adalah sebagai berikut:

a) Komputer

Komputer adalah perangkat untuk membangun sistem aplikasi mobile learning. Dalam hal ini adala pembuatan program menggunakan bahasa pemrograman

b) Device Smartphone

Device smartphone digunakan untuk pengujian aplikasi yang telah dibuat untuk mengetahui apakah aplikasi yang telah dibuat menggunakan emulator mampu berjalan dengan baik pada smartphone android.

\section{Analisa Sistem}

Pembuatan sistem mobile learning diarahkan pada dua sisi yaitu sebagai berikut :
- Pembuatan mobile learning provider yang merupakan sebuah aplikasi layanan mobile learning berbasisi web di sisi server,

- Pembuatan mobile learning client yang merupakan aplikasi mobile di sisi client yang dapat mengakses layanan mobile learning provider.

1) Data Flow Diagram (DFD)

Untuk pengembangan sistem digunakan data flow diagram (DFD) ${ }^{[3]}$ sebagai media untuk menjelaskan semua alur data beserta proses- proses yang terdapat di dalam sistem. Berikut ini context diagram dari aplikasi mobile learning. DFD level 0 dan sub- sub prosesnya.

a) Context Diagram

Dalam diagram konteks terdapat dua entitas luar yang berhubungan dengan sistem yaitu dosen dan mahasiswa, mahasiswa adalah pengguna aplikasi mobile learning untuk pembelajaran, sedangkan dosen sebagai evaluator atau pendamping mahasiswa apa sistem perkuliahan virtual. Diagram konteks mobile learning dapat dilihat pada gambar berikut:

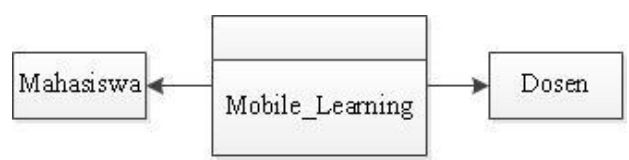

Gambar 1. Diagram konteks mobile learning

b) DFD Level 0

Pada data Flow Diagram level 0 ini, semua aktifitas baik dosen, mahasiswa maupun administrator terlihat jelas, bagaimana dosen meng-upload materi dan tugas serta administrator yang juga membantu mengupload kuis dan maintenance server. Berikut ini adalah gambar dari ERD mobile learning: 


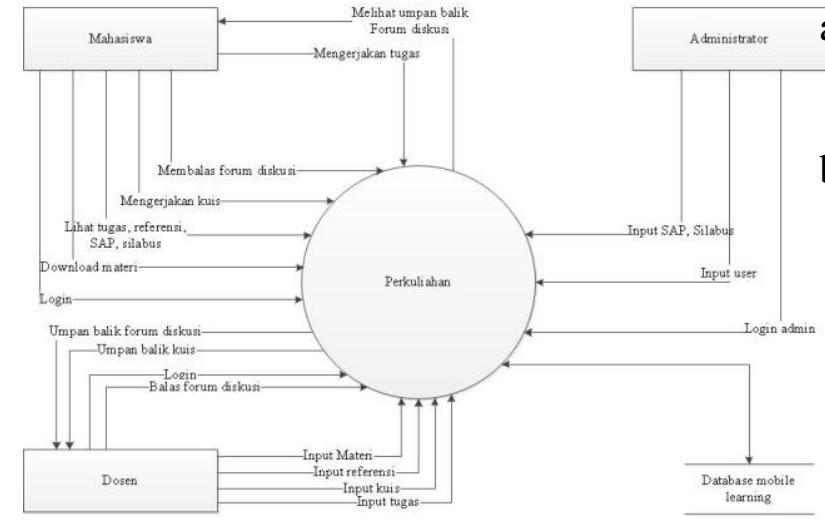

Gambar 2. DFD Level 0 Aplikasi Mobile Learning

2) Entity Relation Diagram (ERD)

Entity relation diagram (ERD) menunjukkan struktur keseluruhan kebutuhan data serta hubungan data- data yang digunakan dalam sistem. Dalam ERD, data tersebut digambarkan dengan menggunakan sistem entitas yang saling terkait. Entity-relationship (ER) diagram (ERD) menyediakan cara untuk mendokumentasikan entitas dalam database bersama dengan atributatributnya. Ada beberapa metode utama untuk menggambar diagram ER yaitu: model Chen (nama pencetus pemodelan $\mathrm{ER}$, Dr Peter Chen PS), Information Engineering (IE, atau "crows feet"), dan Unified Modeling Language (UML) ${ }^{[4]}$. Berikut ini adalah gambar dari ERD dari mobile learning:

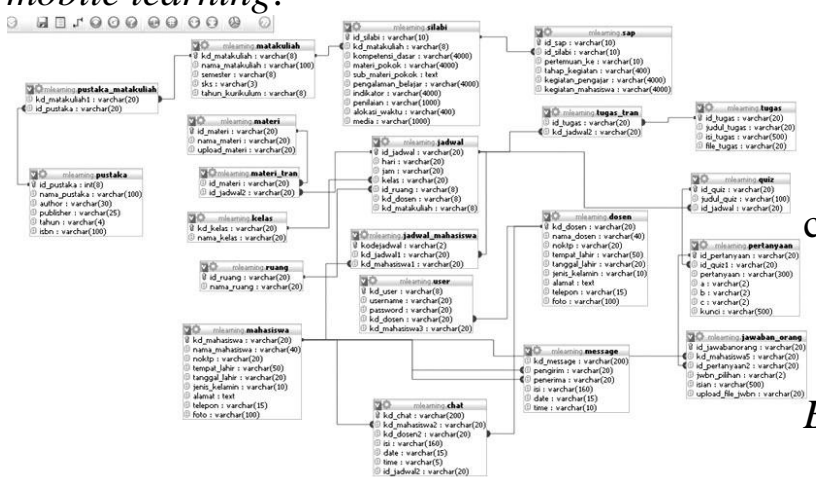

Gambar 3. ERD Aplikasi Mobile Learning

\section{Hasil dan Pembahasan}

\section{A. Rancangan Kerja Sistem}

Pengembangan sistem mobile diarahkan pada dua sisi yaitu sebagai berikut: a) Mengembangkan mobile server yang merupakan sebuah aplikasi layanan mobile berbasis web di sisi server.

b) Mengembangkan mobile client yang merupakan aplikasi mobile di sisi client yang dapat mengakses layanan mobile server.

Berikut ini adalah gambaran arsitektur sistem aplikasi mobile learning.

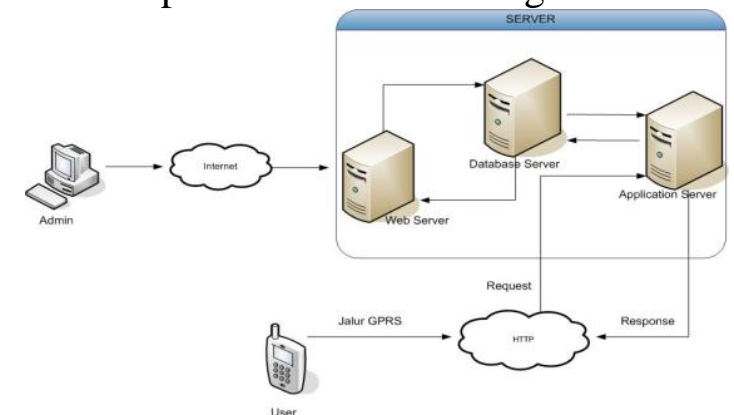

Gambar 4. Arsitektur Sistem Aplikasi Mobile Learning

Dari gambar arsitektur sistem aplikasi mobile learning di atas dapat di lihat bahwa sistem yang akan dikembangkan dibagi menjadi 3 (tiga bagian) sebagai berikut:

a) Bagian admin yang berwenang untuk mengatur konten serta user dengan hak aksesnya.

b) Bagian server yang terdiri dari beberapa 3 (tiga) bagian:

- Database yang digunakan untuk menyimpan konten dari mobile learning

- Aplikasi berbasis web untuk mengatur (manajemen) konten mobile learning.

- Aplikasi server untuk menerima request dan memberi respon client.

c) Aplikasi client (aplikasi mobile learning) yang dikembangkan berbasis symbian yang akan berhadapan langsung dengan client.

\section{B. Cara Kerja Sistem}

Sistem yang akan dibuat terbagi menjadi dua buah sub sistem yaitu sistem yang berjalan pada sisi server dan yaitu sistem yang berjalan pada sisi client. Server merupakan sub sistem yang dijalankan pada web server yang menyediakan layanan mobile yang dapat diakses dan dijalankan oleh sub sistem lain, yaitu mobile learning. 
Berikut ini adalah gambaran dengan flowchart sistem client dan server dalam aplikasi mobile learning:

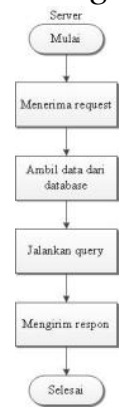

Gambar 5. Flowchart aktivitas server

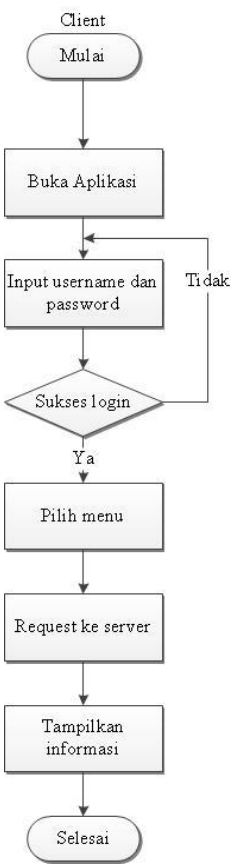

Gambar 6. Flowchart aktivitas client

\section{Desain Interface}

Hal yang perlu diperhatikan dalam mendesain sebuah sistem adalah rancangan tersebut harus dapat memudahkan user dalam menggunakan sistem aplikasi yang dibuat. Sehingga perlu diperhatikan dalam mengatur letak button, textfield, menu, ataupun komponen visual yang lain sehingga tidak membingungkan user dalam pemakaian. Berikut adalah perancangan menu utama sistem aplikasi mobile learning:
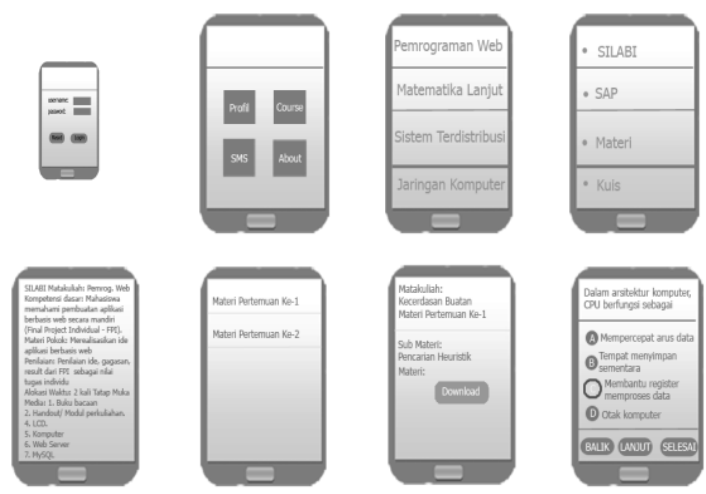

Gambar 7. Desain interface mobile learning

\section{Kesimpulan}

Dari pembahasan pada bagian sebelumya dapat disimpulkan sebagai berikut:

1. Mobile learning merupakan pembelajaran yang cukup prospektif untuk diimplementasikan

2. Kendala pengembangan aplikasi mobile learning adalah keterbatasan sumberdaya dan keragaman platform sehingga perlu rancangan yang mampu mengatasi kendala ini.

\section{Referensi}

1. Georgiev Tsvetozar, Georgieva Evgenia and Smrikarov Angel M-Learning - a New Stage of E-Learning [Journal]. - 2004.

2. Yuan, M.J., 2003. Enterprise J2ME: Developing Mobile Java Applications. New Jersey: Prentice Hall.

3. Ambler, S.W., 2004. The Object Primer Third Edition Agile Model-Driven Development with UML 2.0. Cambridge: Cambridge University Press.

4. Harrington, J.L., 2009. Relational Database Design and Implementation. 3rd ed. Burlington: Morgan Kaufmann.,

5. Safaat Nazrudin Android Pemrograman Aplikasi Mobile Smartphone dan Tablet PC berbasis Android [Book]. - Bandung : Informatika, 2011. 
6. Sholiq, 2006. Pemodelan Sistem Informasi Berorientasi Objek dengan UML. Yogyakarta : Graha Ilmu.

7. Gatot Santoso, Adhi Susanto, Marshal Budi Wardani, 2009. Perancangan Konten M-Learning Dengan Sistem Live Multimedia Berbasis Selular.

8. Patchler, Norbert, 2010. Mobile Learning, Structure, Agency, Practice. London : Springer

9. Kendal, 2003. Analisis dan Perancangan Sistem Jilid 1 Edisi Kelima. Jakarta : PT. Prehanlindo 
